\title{
Joel S. Schuman, Viki Christopoulos, Deepinder K. Dhaliwal, Malik Y. Kahook, and Robert J. Noecker: Rapid Diagnosis in Ophthalmology Series: Lens and Glaucoma
}

\author{
160pp 2008 GBP 41.99, €62.99, US\$69.95 Elsevier Mosby ISBN: 978-0-323-04443-1
}

\author{
Thomas S. Dietlein
}

Received: 27 June 2008 / Accepted: 28 June 2008 / Published online: 12 August 2008

(C) Springer-Verlag 2008

The flexible handy pocket-sized booklet "Lens and Glaucoma" from the "Rapid Diagnosis in Ophthalmology" series (Series Editors: JS Duker and MS Macsai) is editored by JS Schuman, V Christopoulos, DK Dhaliwal, MY Kahook and RJ Noecker, first published in 2008 by Elsevier Inc.

The book has 145 pages divided into eight chapters focusing on congenital abnormalities of the lens, developmental defects and involutional changes of the lens, trauma to the lens, cataract, open-angle glaucoma, closed-angle glaucoma and pediatric glaucoma.

The concept of this reference guide helps the busy clinician to quickly gain information about clinically relevant diagnosis in the cataract and glaucoma field. On the right side of this booklet, the specific diagnosis is usually illustrated by high-quality coloured slit-lamp or fundus images; on the left side, a standardized text gives structured take-home messages to the reader. This structured text is divided into "Key facts", "Mechanism", "Clinical findings", "Ancillary testing", " Differential diagnosis", "Treatment" and "Prognosis". My personal wish for a future edition would be to integrate more clinical illustrations into the vacant right-sided areas of many diagnosis, e.g. posterior lens dislocation or aphakic and pseudophakic iris bombe, because the attractive force of this small atlas is based on its clinically clear and didactically useful illustrations.

This booklet is extremely helpful for students and ophthalmologists in training, but even for the experienced clinician who wants to refresh his knowledge, because a lot of relevant information on the area of lens and glaucoma is transferred by very concentrated text and fine illustrations.

T. S. Dietlein $(\bowtie)$

Department of Ophthalmology, University of Cologne,

Joseph Stelzman Str. 9,

50931 Cologne, Germany

e-mail: thomas.dietlein@uk-koeln.de 